\title{
Evaluating of innovative projects' effectiveness at industrial enterprises
}

\author{
A. Puryaev ${ }^{1, *}$ \\ ${ }^{1}$ Production Management, Kazan Federal University, Naberezhnye Chelny Institute, Kazan, Russia
}

\begin{abstract}
The problem of assessing of innovative projects' effectiveness in industry from the perspective of integrated and compromise approach is actualized. Taking into consideration main directions of the Russian economy development the tooling of efficiency estimation of innovative projects is offered. Evaluating of the effectiveness is presented as solution of multi-criteria optimization problem (using the theory of fuzzy sets and theory of aggregation). The complex of efficiency measurement parameters is developed, which consists of group of critical parameters and economic parameters. Also we offer the mathematical apparatus of innovative projects' efficiency evaluation. The technique, the sequence in the process of evaluating of innovative projects' effectiveness in the industrial enterprises are described in present work.
\end{abstract}

\section{Introduction}

Evaluating of investment projects' effectiveness which are related to the introduction of innovations (substitutions) in the industry, i.e., evaluation of innovative projects in the industry from our point of view can not be based on traditional economic (cost) effectiveness evaluation. It would be even a mistake. The innovation allows to obtain the effect in noneconomic systems, in most cases impossible being adequately assessed from the economical angle, especially with the help of the ruble and using officially accepted valuation methods (the ratio of benefits to cost, the calculation of cash flows, Internal rate of return - IRR, Net present value - NPV and etc.). Implementation of innovative projects can significantly improve the competitiveness of products, reduce production costs and supply the commercial products with new consumer properties. And these properties will give effect in other related sub-systems of activity also, especially in the perspective.

It is obvious that any innovation should be new and practically implemented, bring economic or other benefits. For carrying out the process of innovation requires the effective project is essential. Innovation project is a rationale for the introduction of innovation (substitution in particular) and the implementation process itself innovate by the means of investing [1, $2]$. The innovative project is a form of construction of the innovative activity of the enterprise with a fixed term, steps and resources aimed at specific results. The advisability of investing for the innovation development is necessary to substantiate so the exact innovative project to satisfy not just economic indicators, but a whole range of settings, which are summarized in the only synthesis criterion. Evaluating of innovative projects' effectiveness is a separate area of study in the field of design solutions, and its methodology goes beyond traditional approaches to the analysis of innovation.

\section{Method and research problem}

The objective of the study is to suggest a method (approach) for evaluating of innovative projects' effectiveness in industries, based on a single criterion, which summarizes the different estimated parameters of physical nature.

Research methods and solutions of the problem: analysis of the evaluating parameters used in the industry (literature review); application of the theory of fuzzy sets and aggregation theory in the development of the method (approach) of evaluating of the innovative projects' effectiveness.

Results: The methodology (method) of evaluating the effectiveness of (optimality) innovative projects; complex of partial parameter estimation of innovative industrial settings' efficiency; mathematical tooling that allows you to roll quantitative and qualitative parameters out, different in their physical nature (clear and fuzzy sets).

\section{Research}

To solve the problem must first it is necessary to determine the private parameters of projects' efficiency evaluation. This was achieved by examining existing possible parameters of evaluating in various areas: environmental $[3,4]$, social $[5,6]$,

* Corresponding author: aidarp@mail.ru 
technological [7, 8], economic [9], national security field $[10,11]$ and the scientific-technical field $[1,12]$. A special role in the development of estimation complex of parameters was played by the program of priority development of science and technology and the list of critical technologies approved on the 7 th of July $2011[13,14]$.

In the modern theory of the effectiveness particular relevance is paid to the account in the evaluation process of both quantitative and qualitative factors and parameters different itself and physical nature, which are affecting the efficient operation of production systems in terms of non-linearity (the presence of unforeseen circumstances, "tears", "jumps" or breakthroughs; falls or "explosions", "catastrophes") and uncertainty (under condition of mixed asymmetric information).

The study in a whole has allowed to establish two groups of private valuation parameters of various physical essence, both quantitative and qualitative. Quantitative are encouraged to be submitted in the form of fuzzy sets and fuzzy sets (linguistic variables) with their own term set. The theory of fuzzy sets allows that element can belong to the set, being at the same time with a positive degree of truth, and with a different value of positive degree of truth it cannot belong to the set $[15,16]$. If linguistic evaluations are subjective and approximate (which is often can be observed in our case), then to describe them triangular membership functions suit in this case (the simplest in the calculations). Qualitative are encouraged to be submitted in the form of scoring on a specific scale [8]: four-point scale with five gradations.

For the integration process or generalization of all grades in a single criterion (selection) it is proposed to apply the method of desirability function by Harrington, which is considered to be versatile, accurate and appropriate to the task [17-20] using the method of generalization (aggregation).

\section{Results}

Thus, as a result of the undertaken research of question which is connected with evaluating of innovative projects' effectiveness at the industrial enterprises:

The complex of private evaluation parameters, composed of two groups is worked out:

- a group of critical parameters of efficiency evaluation of innovative projects in industrial enterprises (consists of a sub-group of quality parameters and quantitative parameters). See TABLE I;

- a group of economic parameters of efficiency evaluation of innovative projects in industrial enterprises (officially adopted indicators for assessing the effectiveness of investment projects). See TABLE II.

Table 1. The critical parameters of efficiency evaluation.

\begin{tabular}{|c|c|c|}
\hline № & $\begin{array}{c}\text { Group of critical parameters of } \\
\text { efficiency evaluation }\end{array}$ & The essence and rate setting \\
\hline 1.1 & & Subgroup of qualitative parameters \\
\hline 1 & $\begin{array}{l}\text { Compliance with the priority } \\
\text { areas of science and technology } \\
\text { development ( } 8 \text { directions) and to } \\
\text { the list of critical technologies of } \\
\text { the Russian Federation ( } 27 \\
\text { technologies). }\end{array}$ & $\begin{array}{l}\text { It matches one or more item ( is received and passes the next selection, } \\
\text { evaluation) / does not match any (rejected, excluded as inefficient). The list } \\
\text { of priority areas: } \\
\text { 1. Industry of nanosystems. } \\
\text { 2. Information and telecommunication systems. } \\
\text { 3. Life sciences. } \\
\text { 4. Environmental management. } \\
\text { 5. Transportation and Space Systems. } \\
\text { 6. Energy efficiency, energy conserving, nuclear energy. } \\
\text { 7. Promising kinds of weapons, military and special equipment. } \\
\text { 8. Security and counter- action to terrorism. } \\
\text { The list of critical technologies is presented in reference [14]. }\end{array}$ \\
\hline 2 & $\begin{array}{c}\text { The fact of import and (or) the } \\
\text { uniqueness }\end{array}$ & $\begin{array}{l}\text { If there is the fact of import substitution during the implementation of an } \\
\text { innovative project, the project is accepted (Yes), and passes the next } \\
\text { selection, assessment. If there is no fact- the project is rejected, excluded } \\
\text { both inefficient (No). }\end{array}$ \\
\hline 3 & $\begin{array}{l}\text { The parameter of uncertainty and } \\
\text { risk during the implementation of } \\
\text { the project (UR, points) }\end{array}$ & $\begin{array}{l}\text { Quality parameter of estimation. The following figures, which will be } \\
\text { evaluated and weighed are recommended to include: } \\
\text { - macroeconomic risks (inflation, increasing of the suppliers cost); } \\
\text { • uncertainty of strategic resources supply; } \\
\text { - uncertainty with the sales network (distribution network, distribution } \\
\text { channels); } \\
\text { - uncertainty in transaction costs of the project (explicit and implicit, for } \\
\text { example, the costs of the third parties impact); } \\
\text { - political risks (the change of government, the President, the socio- } \\
\text { economic structure); }\end{array}$ \\
\hline
\end{tabular}




\begin{tabular}{|c|c|c|}
\hline № & $\begin{array}{c}\text { Group of critical parameters of } \\
\text { efficiency evaluation }\end{array}$ & The essence and rate setting \\
\hline & & - uncertainty in the macro-sphere \\
\hline 4 & $\begin{array}{c}\text { Parameter of quality performance } \\
\text { of the project's functions (QPF, } \\
\text { points) }\end{array}$ & $\begin{array}{l}\text { Quality parameter estimation. Under the quality of performance functions } \\
\text { (QPF) we mean quality of the object that performs or should perform the } \\
\text { function (group of functions). By subject the project is meant. For this } \\
\text { functions, requirements should be stated and weighting coefficients } \\
\text { (importance) of each function in the overall composition should be fixed [7, } \\
\text { 8]. }\end{array}$ \\
\hline 1.2 & \multicolumn{2}{|r|}{ The subgroup of quantitative parameters } \\
\hline 5 & $\begin{array}{l}\text { Parameter of national security } \\
\text { (resource security) }\end{array}$ & $\begin{array}{l}\text { Share index of own strategic resources in the value (as of the beginning of } \\
\text { the project prices) of the total volume of strategic resources used in the } \\
\text { project. "Resource security" option should be provided in the form of a } \\
\text { linguistic variable (LV RS) "share of their own strategic resources from the } \\
\text { total volume used in the project strategic resources." The term set is } \\
\text { recommended T (RS) = \{inadmissible, satisfactory, good, excellent }\} \text {. }\end{array}$ \\
\hline 6 & $\begin{array}{l}\text { Parameter of reducing the risk of } \\
\text { industrial catastrophes and man- } \\
\text { made impacts }\end{array}$ & $\begin{array}{l}\text { Greenhouse gas emissions in carbon dioxide equivalent (Emission } \\
\text { Reduction Units). The indicator on greenhouse gas emissions in carbon } \\
\text { dioxide equivalent to the term set T (ERU) }=\{\text { inadmissible, satisfactory, } \\
\text { good, excellent }\} \text {. Quantitative value, measured in tonnCO } \text { a }_{2 e} \text {. Assessment on } \\
\text { the given strict restrictions is imposed by the supervisory authority } \\
\text { (Decision-maker). It is set as a clear set or fuzzy sets (linguistic variable). }\end{array}$ \\
\hline 7 & $\begin{array}{l}\text { Parameter of accelerating the } \\
\text { growth in gross domestic product } \\
\text { (GDP) }\end{array}$ & $\begin{array}{l}\text { The indicator on the average annual growth rate of the real potential added } \\
\text { value (in constant prices of the base year), \%. For the base year the year of } \\
\text { the beginning of the project should be taken in the case of common } \\
\text { framework adopted absence. For LV T } \Delta \mathrm{AV} \text { term set } \mathrm{T}(\mathrm{T} \Delta \mathrm{AV})= \\
\text { \{inadmissible, satisfactory, good, excellent }\} \text { is recommended [7]. }\end{array}$ \\
\hline
\end{tabular}

Table 2. The economic parameters of efficiency evaluation.

\begin{tabular}{|c|c|c|}
\hline № & $\begin{array}{l}\text { Group of } \\
\text { economic } \\
\text { parameter } \\
\text { s of } \\
\text { efficiency } \\
\text { evaluation }\end{array}$ & The essence and rate setting \\
\hline 8 & $\begin{array}{l}\text { Net present } \\
\text { value } \\
(N P V) \text {, rub. }\end{array}$ & $\begin{array}{c}\text { Quantitative indicator of } \\
\text { "Cashflow" methodology. It } \\
\text { should be compared with the } \\
\text { strict restriction or desirable } \\
\text { level set by the investor and (or) } \\
\text { the decision-maker. }\end{array}$ \\
\hline 9 & $\begin{array}{l}\text { Internal } \\
\text { rate of } \\
\text { return } \\
(I R R), \%\end{array}$ & $\begin{array}{c}\text { Quantitative indicator of } \\
\text { "Cashflow" methodology. It } \\
\text { should be compared with the } \\
\text { strict restriction or desirable } \\
\text { level set by the investor and (or) } \\
\text { the decision-maker. }\end{array}$ \\
\hline 10 & $\begin{array}{c}\text { Investment } \\
\text { payback } \\
\text { period } \\
\text { (discounted } \\
\text { ), } T_{P P}, \\
\text { periods of } \\
\text { Project. }\end{array}$ & $\begin{array}{l}\text { Quantitative indicator of } \\
\text { "Cashflow" methodology. It } \\
\text { should be compared with the } \\
\text { strict restriction or desirable } \\
\text { level set by the investor and (or) } \\
\text { the decision-maker. }\end{array}$ \\
\hline 11 & $\begin{array}{l}\text { Capital } \\
\text { investments } \\
\text { in the } \\
\text { project } \\
(C I) \text {, rub. }\end{array}$ & $\begin{array}{l}\text { Quantitative indicator of } \\
\text { "Cashflow" methodology. It } \\
\text { should be compared with the } \\
\text { strict restriction or desirable } \\
\text { level set by the investor and (or) } \\
\text { the decision-maker. }\end{array}$ \\
\hline
\end{tabular}

The given complex of parameters estimation allows to implement comprehensive complex approach to evaluating of the innovative projects' effectiveness. Evaluating the effectiveness of innovative projects becomes the task of multifactor optimization, not only for obtaining the cost economic benefit.

1. The mathematical apparatus that allows to roll quantitative parameters out different in the physical essence (in the form of clear and fuzzy sets) in a single optimization criterion.

To solve this optimization problem the desirability function method by Harrington $[17,19]$, which is:

$$
\begin{gathered}
d_{i j}=e^{-e^{-y_{i j}^{\prime}}} \\
y_{i j}^{\prime}=\frac{\left(y_{\max }-y_{i j}\right)}{y_{\max }} \\
y_{i j}^{\prime}=\frac{\left(y_{i j}-y_{\min }\right)}{y_{\text {min }}},
\end{gathered}
$$

where $d_{i j}$ - private desirability function with oneside constraint for the $i$-parameter of $j$-innovation project; $y_{\max }, y_{\min }$ - upper and lower limits of unilateral restrictions on the $i$-parameter private; $y_{i j}^{\prime}-$ coded (normalized) value of $i$-private parameter of $j$ innovation project, translated to the desirability scale.

Generalized desirability function by Harrington (optimization criterion) of $j$-innovation project $\left(D_{j}\right)$ is defined as the geometric average of ratio by the formula:

$$
D_{j}=\sqrt[n]{d_{1 j} \cdot d_{2 j} \cdot d_{3 j} \cdot \ldots \cdot d_{i j} \cdot \ldots \cdot d_{n j}}
$$

To transfer the parameters of evaluation, presented in the form of linguistic variables (fuzzy sets) in the scale of desirability we have develop our value transfer mechanism of the membership function in the 
desirability function values [18]. On Figure 1 is a schematic example of the graphic transfer mechanism for parameter estimation "Parameter of national security (resource security)."

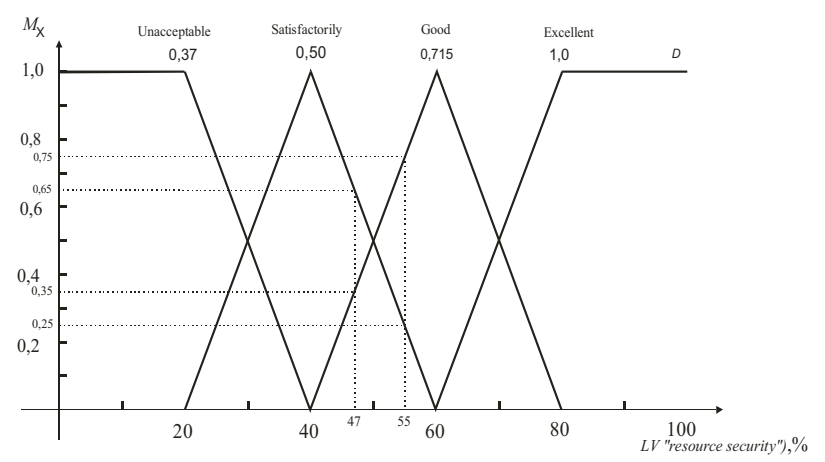

Fig. 1. The functions belonging terms of linguistic variables "Parameter of national security" (LV "resource security").

Below is the method itself (method of approach) of evaluation of innovative projects' effectiveness in the industry.

2. The technique (method, approach) for evaluating the effectiveness of innovative projects at the industrial enterprises has the following strict sequence.

a) Establishing of assessed innovative projects compliance to the presence of private valuation parameters. The possibility of assessment of all the submitted projects of the private parameters would be discovered (see. TABLE I, TABLE II). If all the innovative projects have values to estimated parameters of evaluation, they are comparable (identical), and they can be compared with each other using the results of evaluation. In the case when one project is evaluated so this evaluation step in the procedure is omitted.

b) Setting of limits from the part of the investor (or decision-maker), the supervisory authorities from the values of evaluation parameters in both groups (TABLE I, TABLE II) and their status (min, max, desirable, strict).

c) Transferring of values of critical parameters group (TABLE I) in the value of the desirability function. According to the parameters 1 and 2 subgroup of quality settings is necessary to set private functions of desirability by the following rule. Parameter 1 "matches" $-d=0,37$; "does not match" $-d=0$ (innovative project is rejected). Parameter 2: "Yes" $-d=0,37$; "No" $-d=0$ (innovative project is rejected). For the rest of the parameters (qualitative and quantitative) of this group it is necessary to translate values into the meanings of desirability by Harrington according to formulas (1), (2), (3).

d) Calculating of the desirability of a generalized desirability function on the group of critical parameters according to the formula (3). As a result the synthesis intermediate criterion $D_{l-7 j}$ will be received, which allows to reject the options of innovative projects with strict non-compliance with the limits specified by decision-makers (investors, the supervisory authority) according to a group of critical parameter estimates (7 parameters), i.e. when $D_{1-7 j}=0$. e) Transferring of values of parameter group of economic parameters (TABLE II) to the desirability function values using the formula (1), (2) and (3).

f) Calculating of the desirability generalized function (optimization criterion) $D_{j}$ and thus making an assessment of an innovative project effectiveness or setting of the optimal variant of the innovation project (if it is necessary to choose among the existing alternatives). The formula for the calculation is as follows:

$$
D_{j}=\sqrt[n]{D_{1-7 j} \cdot d_{8 j} \cdot d_{9 j} \cdot d_{10 j} \cdot d_{11 j}}
$$

where $D_{1-7 j}$ - generalized desirability (parameter) of $j$ innovative project for a group of critical parameter estimates ( 7 parameters);

$d_{8 i}, d_{9 i}, d_{10 i}, d_{11 i}$ - ratios of desirability group of economic parameters (numbered 8,9,10 and 11 of TABLE II, respectively).

\section{Conclusion}

Evaluating the effectiveness of innovative projects at the industrial enterprise is a multi-criteria task. The effectiveness of innovative projects should be assessed not only by economic indicators, but with a whole parameter complex of evaluating different physical essence. It is necessary to assess the impact of innovation on the quality of life in general. The developed method (methodology) allows to take into account some critical factors (the most important) in the first place. The author proposes a specific list of qualitative and quantitative parameters of this group, which can be supplemented and modified. Projects that do not comply with the limits for critical parameters of assessment must be rejected as ineffective, which do not allow altering the path of industrial development of the enterprise. The remaining projects that were selected by a group of critical parameters should be evaluated according to traditional economic indicators of efficiency, as well as the final selection of determining the optimal project. An innovative project aimed at qualitative change of the development trajectory of industry and society in general will be appropriate, that is, effective.

The proposed approach (methods, methodology) of assessment the effectiveness of innovative projects includes assessment tools: the conceptual apparatus of evaluation, the complex of the parameters estimation consisting of the two groups, the mathematical apparatus of the assessment and allows in the whole to assess innovative projects for effectiveness (optimality). This method serves as an alternative to the traditional economic evaluation of the effectiveness of innovative projects to officially adopted methodology. This technique has the ability to evolve over time and to take into account future development trends of industry and society as a whole.

A further object of the research is the development phase, bringing to the practical application of software products, which allows to facilitate, modernize and 
instantly respond to emerging changes for improving the methodology for assessing and thus meet the new time challenges in terms of innovative development of the country's economy.

\section{References}

1. A.S. Puryaev, E.A. Rybkina, Innovation, 5, 48-50 (2007)

2. A.S. Puryaev, E.A. Rybkina, Machine builder, 4, 14-18 (2006)

3. E.V. Hlobystov, Assessment and modeling of ecological safety of industrial production: regional aspect

http://www.icfcst.kiev.ua/forform/khlobystov.htm.

4. I.I. Sidorov, Logistic concept of enterprise management (Znanie, St. Petersburg, 2001)

5. B.M. Genkin, M.I. Kozlova, Bulletin ENGECON. Economy Series, 4(5), 3-9 (2004)

6. S.S. Tkachenko, A.S. Doktorovich, Foundry, 8, 2932 (1990)

7. A.S. Puryaev, Modern Applied Science, 9(11), 263275 (2015)

8. G.B. Kac, A.P. Kovalev, Technical and economic analysis and optimization of machines (Moscow, Mashinostroenie, 1984).

9. V.V. Kosov, V.N. Livshic, A.G. Shahnazarova, Methodical recommendations according to efficiency of investment projects (Jekonomika, Moscow, 2000)
10. V. Mau, Economy questions, 2, 4-25 (2007)

11. The Kyoto Protocol to the framework convention of the United Nations on change of climate (2014). www.74rif.ru.

12. L.I. Abalkin, Economy questions, 12, 4-19 (2006)

13. L.Je. Mindeli, S.I. Chernyh, Institute for the Study of Science of RAS (2016). http://www.issras.ru/papers/Prior2011_Mindeli.php.

14. The list of critical technologies of the Russian Federation (Kremlin, 2016). http://kremlin.ru/supplement/988.

15. L.A. Zade, Concept of a linguistic variable and its application to adoption of problem decisions (Mir, Moscow, 1976)

16. K. Asai, Fuzzy systems for management (IOS Press, Amsterdam, 1995)

17. E.C. Harrington, Industrial Quality Control, 21, 10, 494-498 (1965)

18. Aidar S. Puryaev, International Business Management, 9, 856-861 (2015)

19. Chapter 5. The method of desirability function (2016).http://ecograde.bio.msu.ru/files/library/books /1/glava5.pdf.

20. A.V. Ahaev, Algorithm of estimation of functional filling of software products on the basis of an indistinct logical conclusion (2016). http://www.tusur.ru/filearchive/reportsmagazine/2013-28-2/169.pdf. 